\title{
Adult stem cell lineage tracing and deep tissue imaging
}

\author{
Juergen Fink ${ }^{\#}$, Amanda Andersson-Rolf ${ }^{\#} \mathcal{E}$ Bon-Kyoung Koo ${ }^{*}$ \\ Department of Genetics and Wellcome Trust - Medical Research Council Stem Cell Institute, University of Cambridge, Cambridge, CB2 \\ $1 \mathrm{QR}$, United Kingdom
}

Lineage tracing is a widely used method for understanding cellular dynamics in multicellular organisms during processes such as development, adult tissue maintenance, injury repair and tumorigenesis. Advances in tracing or tracking methods, from light microscopy-based live cell tracking to fluorescent label-tracing with two-photon microscopy, together with emerging tissue clearing strategies and intravital imaging approaches have enabled scientists to decipher adult stem and progenitor cell properties in various tissues and in a wide variety of biological processes. Although technical advances have enabled time-controlled genetic labeling and simultaneous live imaging, a number of obstacles still need to be overcome. In this review, we aim to provide an in-depth description of the traditional use of lineage tracing as well as current strategies and upcoming new methods of labeling and imaging. [BMB Reports 2015; 48(12): 655-667]

\section{FROM EARLY CELL TRACKING TO TODAY'S GENETIC LINEAGE TRACING}

How an organism develops, starting from fertilization, is a fundamental question in biology. In the $19^{\text {th }}$ century, conventional embryology described the development of the embryo from fertilization through the various stages of development. Although the fascinating nature of embryonic development was revealed, its description remained at the level of gross morphological changes due to the lack of modern devices as well as the complexity of developmental processes involving millions or billions of cells. In 1974, Sidney Brenner first started investigating the simple invertebrate organism Caenorhabditis elegans (C. elegans) in order to describe development at cellular resolution (1) (Fig. 1A). Its easily visible embryonic development allowed non-invasive microscopic analysis of developmental processes that remained inaccessible to scientists in

*Corresponding author. E-mail: bkk25@cam.ac.uk

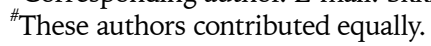

http://dx.doi.org/10.5483/BMBRep.2015.48.12.249

Received 1 December 2015

Keywords: Adult stem cells, Advanced imaging, Intravital imaging, Lineage tracing, Tissue clearing

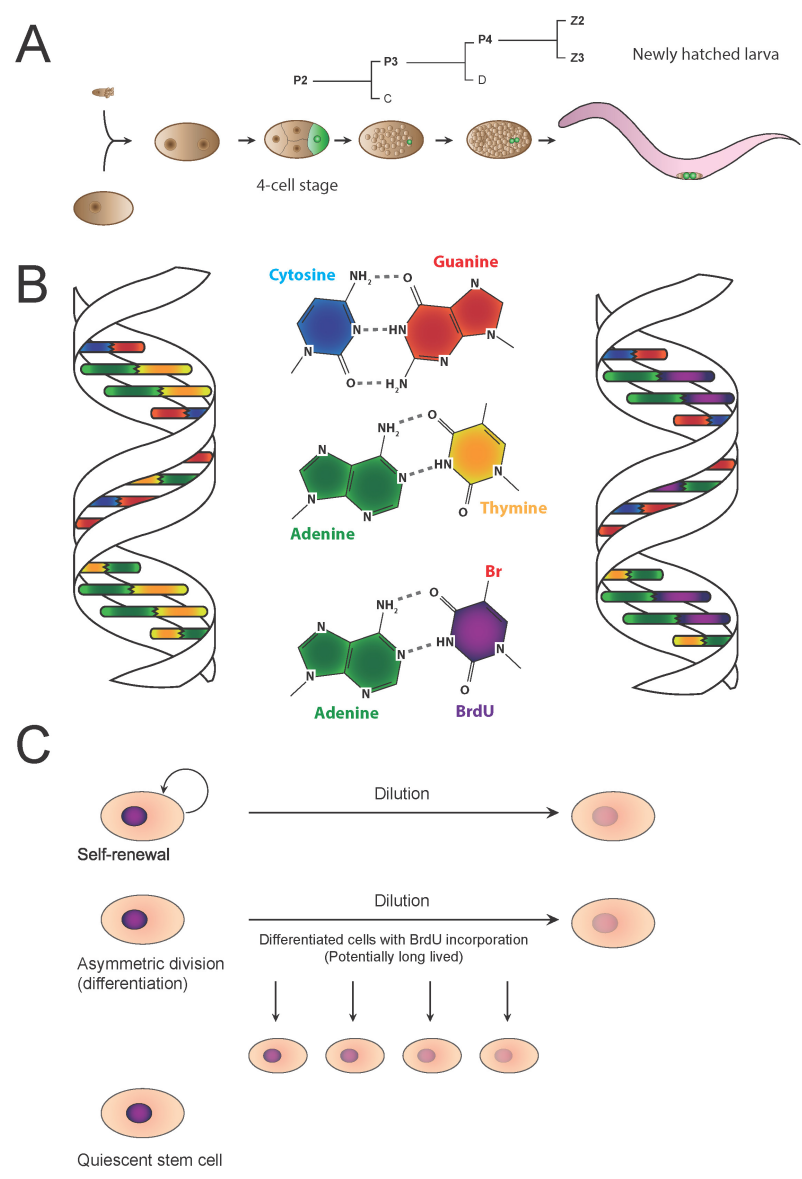

Fig. 1. C. elegans early development and BrdU tracing. (A) Schematic representation of $C$. elegans embryonic development. The germline develops from one single primordial germ cell (PGC) which appears in the early embryo at the 4-cell stage. This PGC will divide and give rise to the two PGCs Z2 and Z3. These PGCs will not divide further until after hatching. Postembryonic divisions result in variable, non-reproducible placement of the daughter cells $(3,4)$. (B) Illustration of bromodeoxyuridine (BrdU), a synthetic nucleoside that is analogous to thymidine, and how it is incorporated into the genome. (C) Representation of how BrdU is diluted during tracing. Rapid self-renewal of the stem cells (top row) will lead to dilution of BrdU. In contrast, quiescent stem cells (bottom row) will retain the BrdU label. During asymmetric self-renewal the progenitor cells divide and give rise to differentiated cells, leading to a dilution of BrdU.

ISSN: 1976-670X (electronic edition)

Copyright (C) 2015 by the The Korean Society for Biochemistry and Molecular Biology

(c) This is an open-access article distributed under the terms of the Creative Commons Attribution Non-Commercial License (http://creativecommons.org/licenses/by-nc/4.0) which permits unrestricted non-commercial use, distribution, and reproduction in any medium, provided the original work is properly cited. 
other organisms. This enabled extensive lineage tracking studies and revealed that at early developmental stages the fate of a specific cell is invariably conserved between individuals. Furthermore, each cell undergoes a defined number of divisions thus resulting in a defined number of somatic cells in the adult (hermaphrodite: 959; male: 1031) (2-4). Nevertheless, limitations of the imaging technology at that time hindered scientists from tracking cell divisions in the later embryo. Thus, the advancement of imaging technology to visualize cellular events was predicted to lead to a deeper understanding of developmental processes.

The labeling of specific cells is one method employed to visualize subsequent cellular events. This represents an improved tracking strategy for the later stages of development, when millions of cells are present. A simple example is the labeling of proliferating cells by incorporation of radioactive nucleoside or nucleoside analogues such as 5-bromo-2'deoxyuridine (BrdU) (Fig. 1B). BrdU had first been described as an antagonist of the terminal steps of DNA-thymine synthesis in 1958 by Kit et al. (5). The use of BrdU incorporation for cell lineage tracing experiments became possible following the development of monoclonal antibodies against BrdU-containing DNA by Gratzner in 1982 (6). In the following years, BrdU incorporation was used extensively to study cell proliferation (7-12) and to label proliferative cells in order to trace their fates in various organ systems (13-17). However, BrdU is diluted following each cell division and is eventually lost in rapidly dividing cells as newly synthesized, unlabeled nucleotides are incorporated into the genome (Fig. 1C). Therefore, BrdU incorporation is useful only in studying cell proliferation, short term lineage hierarchy and label-retention.

Recent advances in genetic manipulation techniques have facilitated the development of genetic labeling strategies that allow the long term labeling of both cycling and quiescent stem cells as well as the permanent tracing of all their descendants. One of the most important tools in performing lineage tracing studies in mice is the Cre/loxP site-specific recombination system first described in the bacteriophage P1 in 1984 by Abremski et al (18). This system allows genetic manipulation by Cre-mediated recombination of LoxP sites integrated into the genomic regions of interest. Further development of a ligand-dependent Cre recombinase - CreERT2 - additionally enabled scientists to temporally control the recombinase activity through the administration of inducing agents (19). For lineage tracing studies, two genetic tools needed to be combined: i) CreERT2 expression under the control of a cell type-specific promoter and ii) reporter gene expression that can be induced upon Cre activity, thus allowing heritable expression of active reporter genes in all progeny. Initially, $\beta$-galactosidase (LacZ) was used as a reporter gene $(20,21)$ (Fig. 2A). Nowadays, single (22-24) to multi-color fluorescent proteins $(25-27)$ are widely utilized for lineage tracing (Fig. 2B, C).

In this review we will discuss recent lineage tracing studies and quantification tools as well as novel live imaging ap- proaches to give an overview of existing techniques and to outline future directions in the field of modern adult stem cell tracking and fate choice studies.

\section{MODERN LINEAGE TRACING STUDIES IN ADULT TISSUES}

Recent lineage tracing studies with temporally regulated CreER recombinase and reporter lines have revealed details about the

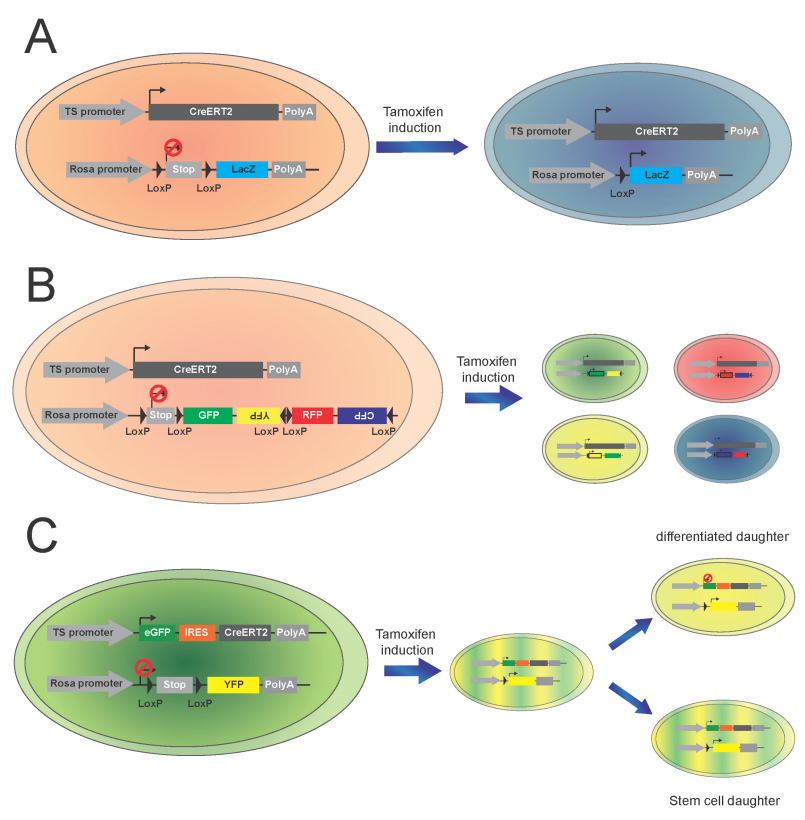

Fig. 2. Examples of different reporter lines. (A) LacZ reporter system in which Cre-mediated excision of the STOP cassette results in lacZ expression, which can later be visualized by X-gal staining. The expression of Cre recombinase is driven by a cell-type or tissue specific (TS) promoter. Tamoxifen administration induces recombination and subsequent LacZ expression in CreERT2 expressing cells. The genetic label is inherited by all daughter cells allowing tracing of the progeny of individual labelled cells. (B) Multi-color reporter. In this system the administration of tamoxifen leads to random recombination of four fluorescent proteins (GFP, YFP, CFP and RFP). Subsequently, the cells expressing CreERT2 under a tissue specific (TS) promoter will also randomly express one of the four colors. The genetic label is inherited by all daughter cells allowing tracing of the progeny of individual labelled cells in one of four colors. (C) eGFP-IRES-CreERT2 cassette. Expression of GFP by a cell-type or tissue specific (TS) promoter mediates green fluorescent labeling of the cell type of interest. The bicistronic eGFP-IRES-CreERT2 construct allows for inducible recombination in the GFP labelled cell population. Combined with a fluorescent reporter, this results in the expression of a second fluorescent protein under a ubiquitous promoter (here Rosa-YFP). In a stem cell that goes through asymmetric division, the daughter cell that remains a stem cell will express both colors (from the ubiquitous and cell-type specific promoter) while the daughter cell that differentiates and thereby turns off the cell-type specific promoter will only be labeled in one color (driven by the ubiquitous promoter). 
homeostatic turnover of multiple tissues and about underlying cellular plasticity in homeostasis, injury response and cancer formation. An excellent example is the study of Lgr5-expressing stem cells in the small intestine and colon (28). In a previous study, the group of Hans Clevers identified Lgr5 as a Wnt target gene whose expression is spatially restricted to the base of intestinal crypts $(29,30)$. They then designed a bicistronic construct - GFP-IRES-CreERT2 - to be inserted into the endogenous Lgr5 locus, which allowed expression of 2 useful proteins (GFP for visualization and CreERT2 for time-controlled recombination) under the control of the Lgr5 promoter (See Fig. 2C for an example of this bicistronic construct in combination with Rosa-YFP reporter). Using this novel strategy combined with the Rosa26-LacZ reporter they showed that the $\mathrm{Lgr}^{+}$crypt base columnar (CBC) cell population maintains itself for over a year and gives rise to all lineages present in the intestinal epithelium, therefore identifying the $\mathrm{Lgr}^{+}$population as intestinal stem cells (28) (Fig. 3). Similar lineage tracing analysis identified additional $\mathrm{Lgr}^{+}{ }^{+}$stem cell populations in other tissues such as the colon, the hair follicle and the pylorus of the stomach $(16,31)$. These studies nicely illustrate

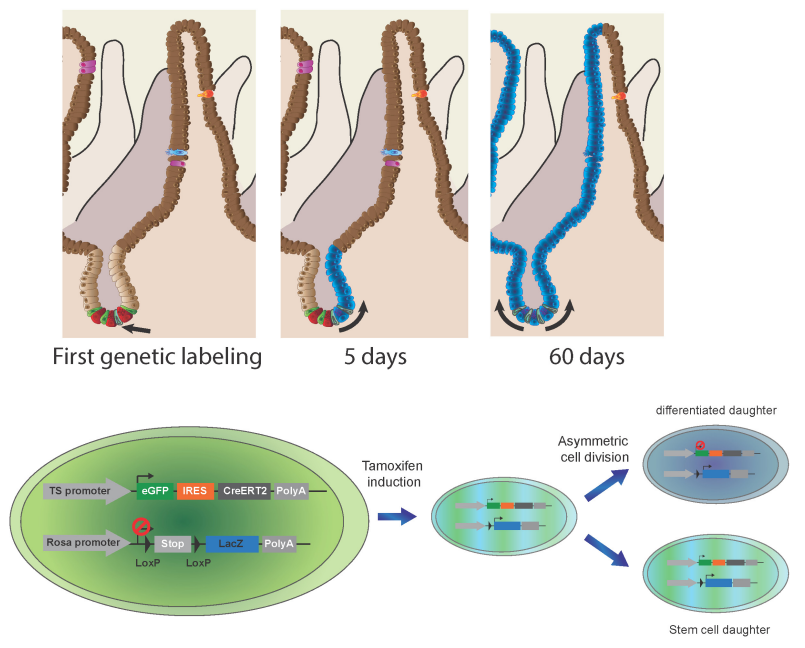

Fig. 3. Lineage tracing of $\mathrm{Lgr}^{5+}$ intestinal stem cells using the lac $Z$ reporter system. Lineage tracing of $\mathrm{Lgr}^{5+}$ stem cells. An eGFP-coupled, tamoxifen inducible knock-in mouse is used in which the expression of eGFP and CreERT2 is driven by the LGR5 promoter. All $\mathrm{Lgr}^{5+}$ stem cells express eGFP. Following the administration of tamoxifen, recombined stem cells express Lgr5 promoter driven eGFP and ubiquitous promoter driven LacZ. Upon division, daughter cells of $\mathrm{Lgr}^{5+}$ stem cells either remain as stem cells expressing both GFP and lacZ, or differentiate turning off the expression of Lgr5 expressing only the lacZ reporter gene. Lac $^{+}$cells derived from labelled $\mathrm{Lgr}^{5+}$ stem cells quickly move upwards towards the villi (day 5). Neutral drift within the stem cell zone results in complete labeling of the entire crypt within several weeks. All cells of the adjacent villi have been replaced by labelled progeny of one initially labelled $\mathrm{Lgr}^{5+}$ stem cell (day 60). the utility of lineage tracing as a tool to elucidate the stem cell properties of potential stem cell populations.

\section{IMAGING TECHNOLOGIES ENHANCE TISSUE-WIDE LINEAGE TRACING STUDIES}

Unlike the highly ordered epithelium of the intestine, other epithelial structures (e.g. in lung, pancreas, liver and mammary glands) have a highly branched morphology that necessitates the use of sophisticated 3D imaging of thick tissue to analyze the entire lineage tracing event. In today's confocal microscopes, a selective filter only allows light of the desired wavelength to pass while a pinhole before the detector blocks any out-of-focus light to generate the corresponding emission image of the excited specimen spot. The resulting image is generated point by point, allowing in-focus imaging from selected specimen depths. Subsequent 3D-reconstruction can help in turn to identify stem- or progenitor cell-derived clonal expansions in lineage tracing experiments. However, the limitations of confocal laser scanning microscopy include photobleaching, laser light scattering, emission light scattering and imaging time (32-34).

The development of 2-photon microscopy aimed to circumvent these photo bleaching and laser light scattering problems by using photons of longer wavelengths (lower energy) that can excite fluorescent proteins or dyes only in a defined focal plane (34). Where the paths of both photon beams cross, simultaneous absorption of the individual photons leads to a selective increase in photon energy (35-37) which subsequently reaches the required energy to excite the fluorescent dye or protein of interest.

Light-sheet microscopy represents another alternative to conventional confocal microscopy, with improved imaging speed due to illumination and detection of entire focal planes at the same time (Table 1). This technology presents unprecedented low photo toxicity at very high image acquisition speed optimal for live imaging. The development of smaller light sheets, for higher axial excitation resolution, in combination with higher numerical aperture (NA) lenses for higher axial detection resolution enabled the fast detection of molecular processes like transcription factor binding kinetics in up to $35 \mu \mathrm{m}$ thick live mouse embryonic stem cell spheroids (38). Alternatively, using lower NA lenses and thicker light sheets, this technology can be used to image entire small organisms or organs while maintaining high speed image acquisition, though at lower resolution (For technical details see: 38-42). Due to its superior performance in cell viability, light sheet microscopy has been used extensively for live imaging of developmental processes in e.g. C. elegans and Drosophila melanogaster, Tribolium castaneum, zebrafish or mouse embryos $(38,40,41,43-49)$. In the field of adult stem cell lineage tracing, the light sheet microscopy technology holds particular promises in live tracking of stem cell mediated homeostasis and for the observation of injury mediated repair mechanisms. 
Table 1. Fluorescence Microscopy for Lineage Tracing Imaging

\begin{tabular}{|c|c|c|c|c|}
\hline & $\begin{array}{c}\text { Standard Fluorescence } \\
\text { Microscope }\end{array}$ & $\begin{array}{l}\text { Laser scanning Confocal } \\
\text { Microscope }\end{array}$ & $\begin{array}{l}\text { 2-photon Confocal } \\
\text { Microscope }\end{array}$ & Light Sheet Microscope \\
\hline Imaging depth & $\begin{array}{l}\text { All (Out of focus because } \\
\text { of lacking focal plane } \\
\text { selection) }\end{array}$ & Up to $500 \mu \mathrm{m}$ & Up to $1 \mathrm{~mm}$ & Up to $500 \mu \mathrm{m}$ \\
\hline Image plane selection & No & Yes & Yes & Yes \\
\hline Photo bleaching & $\begin{array}{l}\text { Medium - High (LED light } \\
\text { for reduced bleaching) }\end{array}$ & Medium & Low & $\begin{array}{l}\text { Very Low (Due to } \\
\text { increased imaging speed } \\
\text { and selected illumination) }\end{array}$ \\
\hline Cell Viability & $\begin{array}{l}\text { Low - High } \\
\text { (LED light for increased } \\
\text { cell viability) }\end{array}$ & High & High & $\begin{array}{l}\text { Very High (Due to } \\
\text { increased imaging speed } \\
\text { and selected illumination) }\end{array}$ \\
\hline Excitation & All & $\begin{array}{l}\text { Entire specimen in } \\
\text { objective focal axis }\end{array}$ & $\begin{array}{l}\text { Limited to objective focal } \\
\text { volume }\end{array}$ & $\begin{array}{l}\text { Entire specimen in focal } \\
\text { plane }\end{array}$ \\
\hline Laser light scattering & N/A & High & Low & Very high \\
\hline Emission light scattering & N/A & $\begin{array}{l}\text { Dependent on specimen } \\
\text { and image depth }\end{array}$ & $\begin{array}{l}\text { Dependent on specimen } \\
\text { and image depth }\end{array}$ & $\begin{array}{l}\text { Dependent on specimen, } \\
\text { mounting, and image } \\
\text { depth }\end{array}$ \\
\hline Price & Low - High & High & Very High (Laser) & Low - Very High \\
\hline Main Limitations & $\begin{array}{l}\text { Imaging Depth, } \\
\text { Z-resolution }\end{array}$ & $\begin{array}{l}\text { Imaging time, } \\
\text { photo-damage }\end{array}$ & Imaging time, heat, price & $\begin{array}{l}\text { Imaging depth (Steric } \\
\text { hindrance), price, } \\
\text { specimen mounting is } \\
\text { crucial, implementation } \\
\text { of most recent } \\
\text { optimizations ongoing }\end{array}$ \\
\hline Main advantages & $\begin{array}{l}\text { Accessibility, very good } \\
\text { for } 2 \mathrm{D} \text { of thin sections, } \\
\text { additional deconvolution }\end{array}$ & Accessibility, 3D imaging & $\begin{array}{l}\text { Imaging depth, low } \\
\text { photodamage }\end{array}$ & $\begin{array}{l}\text { Imaging speed, very low } \\
\text { photodamage, specimen } \\
\text { size }\end{array}$ \\
\hline
\end{tabular}

A few stem cell lineage tracing studies have utilized this novel technology. One example is the identification of perivascular collagen $1 \alpha 1$ cells as the main source of the cellular composition of the fibrotic scar after contusive spinal cord injury (50). Commercially available light sheet microscopes and readily available access to this novel technology in imaging facilities will speed up adult stem cell lineage tracing experiments.

Currently light sheet microscopy is being used for small organs or organisms (up to a few hundred $\mu \mathrm{m}$ ) at high axial resolution using high NA lenses. However, the use of these lenses results in steric hindrance due to the required working distance of each lens (38). Therefore, Imaging of larger specimens (up to $\mathrm{cm}^{2}$ ) is performed using low NA lenses at a lower axial resolution. The main obstacle of light sheet microscopy as well as all other imaging techniques aiming at deep tissue visualization is optical heterogeneity of the specimen and the resulting light refraction, which causes light scattering and reduces the number of photons reaching the detector or camera.

To circumvent this problem, another strategy that aims to aid visualization of thick specimens by reducing the light scattering properties of intact tissues and therefore increasing overall optical transparency has been developed. In 1914, Werner Spalteholz performed pioneering studies in this field by using organic solvents to reduce light scattering within tissues (51).
Commercially available mounting reagents, e.g. RapiClear ${ }^{\mathbb{R}}$ (RC), can improve the light permeability of samples by minimizing light scattering at the interface between coverslip and specimen and within the specimen itself. The refractive index (RI) of RC 1.52 is around $1.52 \mathrm{nD}$, close to that of lipid membranes, which are a major source of light scattering in the tissue. Additionally, the RI of RC 1.52 is close to that of glass. If oil lenses are used, all Rls on the path from the samples to the cover slip and objective are consistent, increasing the resolving power as well as signal brightness.

Several additional clearing reagents have been described in recent years to perform clearing and subsequent $3 \mathrm{D}$ imaging of whole organs $(39,52,53)$. These techniques have further been optimized to reduce fluorescent quenching during the process of clearing (54-57). All of these tissue clearing strategies aimed at increasing the light permeability of tissues in order to visualize expressed fluorescent proteins, but limited antibody penetration poses another challenge to the molecular interrogation of intact tissues that needed to be overcome. Chung et al developed an ionic extraction technique, named CLARITY (originally an acronym for Clear Lipid-exchanged Acrylamide-hybridized Rigid Imaging/Immunostaining/In situ hybridization-compatible Tissue-hYdrogel), to remove the lipid bilayer of cells while maintaining the structural integrity of the 


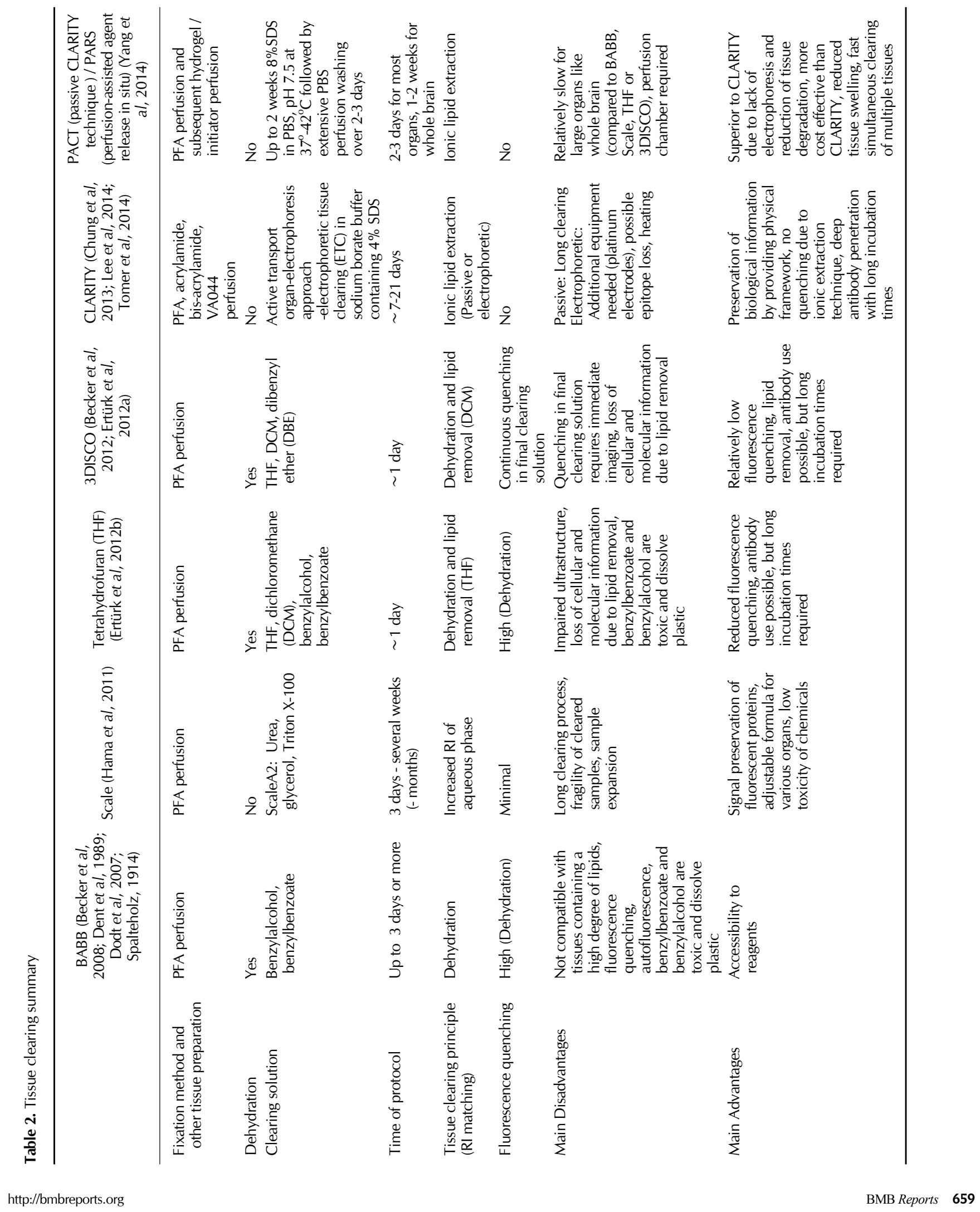


tissue (58). First, the tissue of interest gets perfused with a combination of hydrogel monomers, formaldehyde and polymerization initiators (at $4^{\circ} \mathrm{C}$ ). After incubation at $37^{\circ} \mathrm{C}$, the hydrogel monomers polymerize, incorporating biomolecules within the mesh of hydrogel and stabilizing the 3D structure of the tissue. In the second step, lipids and other unbound biomolecules can be extracted by active electrophoresis. Besides the obvious effect of optical tissue clearance, the hydrogel mesh in combination with lipid extraction allows increased antibody penetration and reduced loss of proteins compared to other clearing or permeabilization protocols $(42,59)$. Yang et al reported a perfusion-based modification of the CLARITY protocol with superior tissue clearing speed and reduced risk of tissue degradation or overheating (PACT: Passive CLARITY Technique / PARS: Perfusion-assisted Agent Release in Situ) (60) (Table 2). The application of this technique in combination with modern deep tissue imaging and long term lineage tracing studies of potential organ-specific progenitor or adult stem cell populations will enable 3D analysis in various tissues.

\section{MATHEMATICAL MODELING TO UNDERSTAND UNDERLYING CELLULAR DYNAMICS}

The development of better 3D imaging techniques resulted in the capability to acquire induced clonal expansion data from lineage tracing that enables additional retrospective analysis of clonal behavior. Although analysis of individual time points after labeling of specific stem cell populations only reveals restricted information about the underlying clonal expansion, the consecutive analysis of multiple time points and subsequent integration of the acquired data allows the development of mathematical models which permit a glimpse of clonal behavior on a population level. In other words, the acquisition of clonal expansion data at multiple time points and in multiple biological replicates provides the dynamic information required to understand both the kinetics of cell proliferation and stem cell fate behavior. Two conceptual approaches are frequently taken to infer information about these two biological concepts. Here we outline the main strategies that can be followed to infer information about biological processes by utilizing mathematical modeling approaches in combination with adult stem cell lineage tracing experiments.

\section{Analysis on a population level}

To decipher the kinetics of cell proliferation by lineage tracing analysis, scientists and mathematicians use quantitative population average measurements following a continuous labeling approach such as BrdU incorporation. Following the BrdU incorporation, over time all newly generated cells are going to be labeled, ultimately resulting in labeling of all cells at a rate that depends on both the rate of stem cell divisions $(\lambda)$ and the rate of differentiated cell loss $(\Omega)$. Assuming a simplified two compartment model in which cell divisions and cell loss occur independently of each other, the behavior of the labeled cell population is described by the fraction of labeled cells over all cells as a function of chase time: $\mathrm{f}(\mathrm{t})=$ $\left(1-p e^{-2 \lambda t}-(1-p) e^{-\Omega t}\right) \times 100 \%$, with the fraction of proliferative cells $p=1 /(1+\lambda / \Omega)$ (61). For homeostatic conditions, the curve resulting from this model is entirely described by only cell division $(\lambda)$ and loss rate $(\Omega)$, and average information about both biological processes can be inferred using mathematical modeling in combination with this simple labeling approach and quantitative data acquisition. Similarly, label dilution assays can be utilized to describe proliferation kinetics. However, as both strategies rely on population average measurements, these approaches can only give information about the stem cell behavior on a population basis. Beyond the average information on cell division and extinction, individual cell fate decisions underlying the observable population dynamics should be interrogated using a clonal approach.

\section{Analysis on a clonal level}

Understanding individual stem cell fate behavior requires clonal assays which in many cases are achieved by genetic labeling, utilizing the inducible CreERT2 system. Assuming that clonal labeling is achieved, a snapshot of clone size and cellular composition of multiple clones at a given time point should reflect all possible fate paths that led to the recorded clonal data. By increasing the number of analyzed clones and time points, the empirically observed frequency of clones in a certain fate path becomes proportional to the actual chance of that particular fate path. The application of mathematical models in this context is dependent on the initial hypothesis that needs to be tested to dissect a given biological process. One very good example of how mathematical modeling can be applied to clonal data is the description of neutral drift within the $\operatorname{Lgr} 5^{+}$intestinal stem cell population towards monoclonality. The mathematical principles that underlie this analysis have been described in detail in the original paper by Snippert et al and in a subsequent paper by the group of Jacco van Rheenen (26, 62). Here we want to summarize the most important criteria that need to be considered for the experimental design. For this type of study it is important that the induction frequency is low enough so that subsequent tracing events have a defined high chance of being the progeny of a single labeled cell. Additionally, the scoring method needs to be well defined to address the hypothesis in question. Scoring all clones by size can be helpful to decipher the variability in fate paths that a single cell can follow, but to understand stem cell dynamics in detail it might be important to score clones by taking additional criteria into consideration. In this example, to decipher stem cell population behavior on a clonal level, all clones that have entirely left the stem cell niche (i.e. no more $\operatorname{Lgr} 5^{+}$stem cell within the clone) and therefore seized to contribute to the stem cell population have been considered as depleted clones. Clones that consist of $6 \mathrm{Lgr}^{+}$and $10 \mathrm{Lgr} 5^{\mathrm{dim}}$ cells were scored as a clone size of 6 . This simplified approach allows for more 
detailed analysis of the stem cell compartment by discarding potentially misleading clone information caused by the high proliferative turnover of the transit amplifying cell population. The resulting clone size distribution describes the clonal behavior within the stem cell population.

Other examples of how lineage tracing experiments in combination with quantitative analysis have contributed to our current knowledge of adult stem cell behavior can be found in multiple studies. In 2007, the group of Philip H. Jones in collaboration with Benjamin D. Simons showed that in mouse tail epidermis only one type of progenitor cell maintains homeostasis, in contrast to the proposed model of two distinct populations of self-renewing stem cells and transit amplifying progenitor cells (63). In the following years, Benjamin Simons has worked together with multiple groups aiming to unravel the underlying cellular mechanisms that govern homeostasis, injury response and malignancies in multiple tissues. His collaborative studies have shed light on adult stem cell behavior in the ear epidermis, the esophagus $(64,65)$ and the intestinal epithelia $(26,66,67)$ in mice. Other studies included the analysis of stem cell behavior in the mouse germ line (68), prostate (69), skin and intestinal tumors (70-72). These examples demonstrate that quantitative analysis of lineage tracing events expands the biological significance of the acquired data, so providing new insights into adult stem cell differentiation and self-renewal.

\section{LIVE CELL IMAGING IN VITRO AND IN VIVO}

In contrast to the retrospective analysis of clonal expansion based on lineage tracing, live imaging allows continuous direct observation of the cells or organism of interest, for a certain period of time. Up until the late 1980s, the conditions during the live imaging process were incompatible with the maintenance of mammalian cells for more than a few hours, thus severely limiting the information that could be gained. In order to study the hierarchy of neural progenitors, Sally Temple placed her microscope inside the incubator and for the first time mammalian cells could be imaged for a longer time period. This was the beginning of the development of incubation chambers $(73,74)$. Today, computerized incubation chambers, microscope stages and major technical advances in the development of microscopes (e.g. two-photon and spinning disc microscopes) combined with rapidly expressed, bright fluorescent proteins have allowed the use of live imaging to monitor biological events in real time $(73,75-78)$. On a cellular level, the application of live cell imaging has been used to monitor the phenotype of rat retinal progenitor cells prior to mitosis in order to determine whether characteristic phenotypes could predict the fate choice (79). At a larger scale, in toto (Latin: as a whole) imaging is commonly applied. As the name implies, the aim is to image and track every single cell movement and division that forms a tissue or organ (80). Since its development in 2003 by Sean Megason and
Scott Fraser, it has been extensively used to study embryonic development. Model organisms such as zebrafish and C. elegans are commonly used due to their suitability for imaging and genetic manipulation, as both zebrafish embryos and C. elegans are small and transparent (81).

While zebrafish embryos develop freely outside of their mother in water, mouse embryonic development takes place inside the uterus. The developmental stages prior to implantation have been extensively studied, as mouse pre-implantation embryos can be isolated and their development can be observed in vitro by live imaging (82-84). Conversely, post implantation events have largely remained elusive as implanted embryos are inaccessible for direct observation. Recently the group of Zernicka-Goetz developed a novel in vitro culture system that allows the live imaging of the previously inaccessible implantation process (85). This exemplifies how novel in vitro culture systems in combination with live imaging can provide knowledge of biological processes and events that would otherwise be inaccessible in vivo.

Another example of how In vitro studies can provide new insights into adult stem cell behavior is the recently developed long term culture of organoids. The organoid culture system, maintained by actively cycling adult stem cells, provides a novel platform to study biological processes involved in the regulation of adult tissue specific stem cells. Organoids are self-organizing 3D structures whose architecture and physiological properties closely resemble the in vivo tissue (86). The development of genetic tool kits, such as retroviral transduction (87), bacterial artificial chromosome (BAC)-transgenesis (88) and CRISPR/Cas genome engineering (89) has allowed cell type- or gene-specific labeling with fluorescent proteins and functional genetics to be performed in this in vitro culture system to study stem cell maintenance, cell fate decisions and cell-cell interactions in combination with live imaging $(86,90)$.

\section{INTRAVITAL IMAGING (IN VIVO LIVE CELL IMAGING)}

The development of advanced in vitro culture systems has enabled studies of in vivo processes otherwise hidden from sight. An alternative has been the development of tools permitting imaging to be performed in vivo to study biological events in living animals. The ability of the firefly (Photinus pyralis) and sea pansy (Renilla reniformis) to biochemically generate light using luciferase enzymes inspired scientists to develop a reporter system, using the same enzymes, allowing the non-invasive tracking of cells $(91,92)$. To date, several transgenic luciferase reporter mice have been generated and used to study metastasis, gene expression and bacterial and viral infections $(92,93)$. Although in vivo bioluminescence imaging has minimal background and a high signal-to-noise ratio, it lacks cellular resolution $(92,94)$. This issue can be circumvented by using confocal and two-photon microscopy in combination with fluorescent reporter mice. The innovation of imaging windows (95) allowed Lehr et al to be among the first to perform intra- 
vital imaging over multiple days $(96,97)$. Ever since, imaging windows for skin, cranial, mammary and abdominal imaging have been developed (98-101) and intravital imaging has been applied to investigate various biological processes in several different research areas, for example angiogenesis, neurobiology, immunology, and cancer biology (99, 102-109). For long-term imaging (days to weeks), tattooed reference marks in combination with vascular and extracellular matrix structures can be used as landmarks to re-identify previously imaged cells (110-112).

An excellent example of the use of intravital imaging in adult stem cell research is from the group of Jacco van Rheenen. Previous studies utilizing lineage tracing managed to delineate the hierarchical organization of squamous skin tumors, intestinal adenomas and glioblastomas $(72,113,114)$. Nonetheless, the static images fail to address the issue of plasticity and individual clone behavior. Using the Lgr5-CreERT2;confetti mouse line (26), van Rheenen and his team confirmed the previously observed neutral drift model and in addition provided insight into the short-term dynamics of the $\mathrm{Lgr}^{+}$stem cells. Even though all $\mathrm{Lgr}^{+}$cells possess long-term self-renewal potential, the stem cells located at the crypt base, called 'central stem cells', have a survival advantage over the 'border stem cells', which are located in the upper part of the niche and can be displaced into the transit-amplifying domain following the division of adjacent cells (107) (Fig. 4).

\section{OUTLOOK}

To date, the technical advancement of microscopes (in both hardware and software) as well as the development of sophisticated molecular and genetic tools has led to a parallel development of live imaging and lineage tracing. In recent years the two have started to come together, a synergy that has led to novel insights ranging from developmental processes to cellular hierarchies within adult tissues and tumors. An obstacle still remaining is the long-term, intravital imaging of deep-tis-

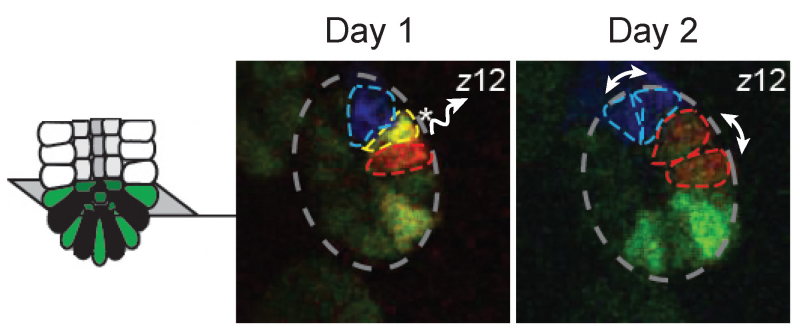

Fig. 4. Intravital imaging of the intestinal stem cell niche. Intravital images of the same intestinal crypt after tamoxifen mediated labelling of Lgr5-CreERT2 expressing stem cells on a confetti reporter background. The panels illustrate how two clones (red and blue) expand on dispense of a yellow clone, which gets pushed out of the stem cell zone. sue, the solution of which would allow the observation of adult stem cell dynamics directly inside organs and tissues. Until this issue is resolved, the development of advanced in vitro culture systems which fully or partially recapitulate the in vivo situation, together with the innovation of new imaging windows, will be of paramount importance. Choosing the appropriate method best suited for the purpose of the experiment is crucial to achieve reproducible results and to draw solid conclusions from the observations.

Despite the existing technical obstacles, there are prospective new techniques and systems providing other highly interesting options. One is magnetic resonance imaging (MRI). It is the least invasive imaging technique (115) and can be applied to large volumes or whole organisms. In addition, it is safe enough to be used as a diagnostic tool (78). However, advanced experimental machines allowing near single-cell resolution in a spatiotemporal manner remain very expensive and are therefore not widely available $(116,117)$. Another major limitation is low contrast and signal strength. To overcome this issue, scientists have been using contrasting agents usually based on gadolinium $\left(\mathrm{Gd}^{3+}\right)$ (118). To use this technique for the purpose of adult stem cell lineage tracing, new genetic labels for MRI-contrasting agents can be used instead of fluorescent (e.g. YFP) or colorimetric (e.g. LacZ) labels. One approach is to utilize divalent metal ion transporters (DMT1) which facilitate the transport of $\mathrm{Mn}^{2+}$ and metabolically biotinylated cell surface protein, which can then be detected using a streptavidin-horseradish peroxidase conjugate in conjunction with a peroxidase-sensitive gadolinium agent (119). Recently, an Oatp1a1 reporter has been described by Patrick et al. This transport protein mediates the uptake of $\mathrm{Gd}^{3+}$ (in the form of gadolinium-ethoxybenzyldiethlenetriamine pentaacetic acid), a clinically approved contrast agent for MRI (120). Genetic modification to generate ferritin-expressing cells has been shown to increase the contrast (121-123). Superparamagnetic iron oxide nanoparticles (SPIONs) have been used as contrast agents to label and track stem cells in rabbit (124), rat $(125,126)$ and human patients $(127,128)$.

Another technical advancement comes from the group of F. Levent Degertekin, which has developed a camera $1.5 \mathrm{~mm}$ in size. Still to be tested on animals, it holds the potential for taking 3D images from inside veins and arteries (129). This type of miniaturization of cameras and detectors, with the option of adding guiding wires or possibly implantation, even if transient, could aid and expand the field of vision for live imaging as well as lineage tracing. Recently, the group of Hongjie Dai developed a method utilizing nanotubes with intrinsic photoluminescence to image the mouse cerebral vasculature without any invasive procedures (except the injection of the nanotubes) (130). These two examples demonstrate how the development of micro- and nanotechnology can facilitate and enable previously unknown imaging possibilities.

Transparency is one of the strongest advantages of using zebrafish and C. elegans for the purpose of imaging. At the same 


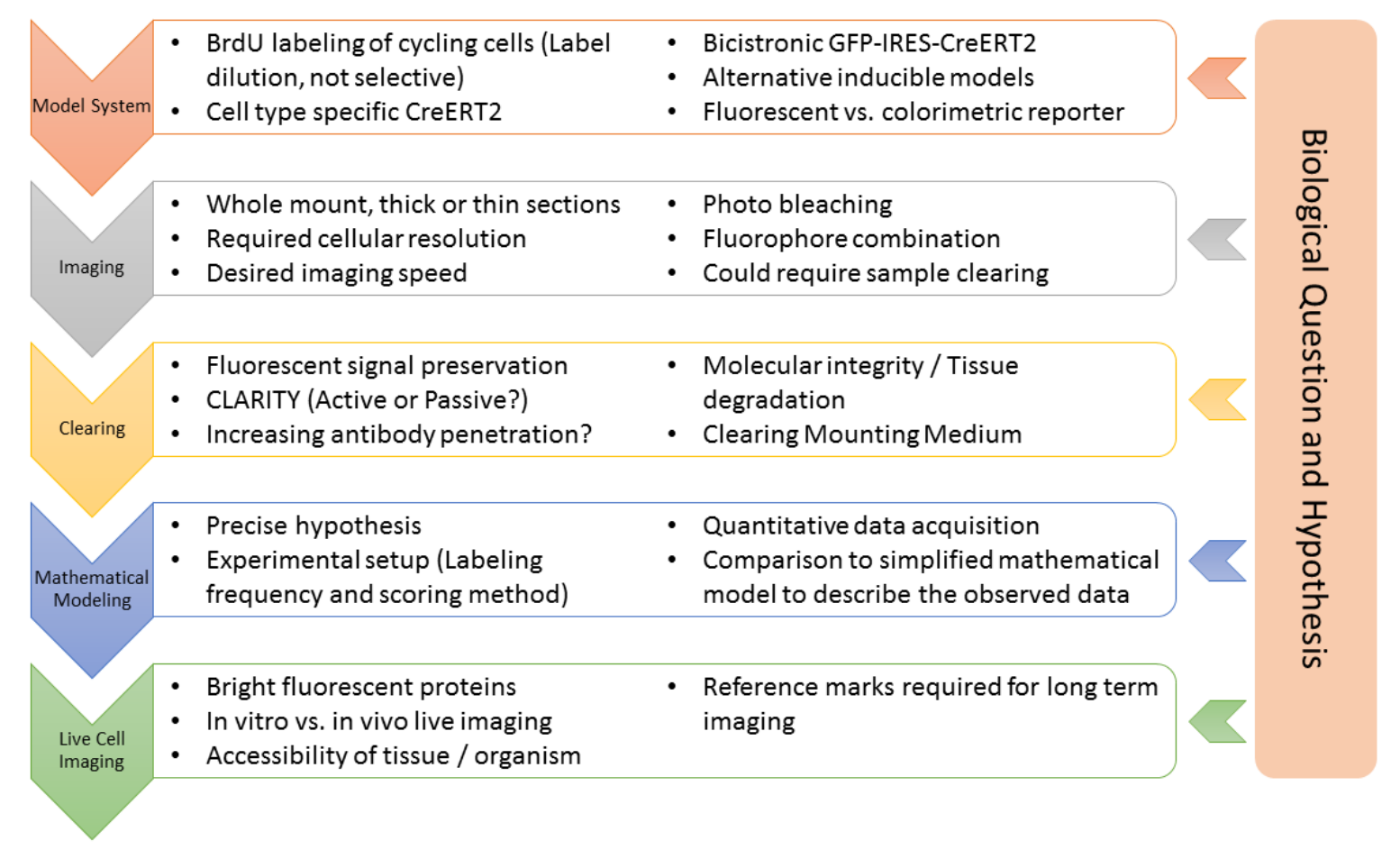

Fig. 5. Overview of available strategies. Lineage tracing experimental design workflow highlighting specific aspects to take into consideration when following a subset or all of the proposed strategies.

time, the lack of transparency is a significant hurdle that obscures vision and imaging of biological processes in many other organisms. Tissue clarification techniques like CLARITY can render some tissue samples transparent and thereby improve imaging conditions (58). However, this procedure cannot be performed on live animals, so while we await the generation of a live transparent mouse it might be interesting to consider model organisms that are naturally transparent. Glass frogs belonging to the family Centrolenidae are, potentially, the highest vertebrate displaying high level in vivo transparency (131). In combination with CRISPR/Cas genome engineering, they might become a valuable model for genetic and live imaging studies to understand tissue homeostasis $(132,133)$.

In the end there will, most likely, never be one single ideal approach. Instead, each research question will require its own optimization with regards to model system (in vitro or in vivo), labeling approach, tissue clearing, image acquisition and relevant mathematical modelling strategies (See Fig. 5 for overview and summary). Together with recent developments and upcoming new systems, lineage tracing and live imaging will provide us with greater details of adult stem cell behavior and tissue homeostasis.

\section{ACKNOWLEDGEMENTS}

We thank Prof Jacco van Rheenen for providing examples of intra-vital imaging. Dr Chris Hindley, Dr Onur Basak and Dr Seungmin Han for comments and proof reading. JF and AAR are supported by the Wellcome Trust and MRC, respectively. BK is supported by a Sir Henry Dale Fellowship from the Wellcome Trust and the Royal Society [101241/Z/13/Z] and receives core support grant from the Wellcome Trust and MRC to the Wellcome Trust - Medical Research Council Cambridge Stem Cell Institute.

\section{REFERENCES}

1. Brenner S (1974) The Genetics of Caenorhabditis Elegans. Genetics 77, 71-94

2. Sulston JE, Schierenberg E, White JG and Thomson JN (1983) The embryonic cell lineage of the nematode Caenorhabditis elegans. Dev Biol 100, 64-119

3. Sulston JE and Horvitz HR (1977) Post-embryonic cell lineages of the nematode, Caenorhabditis elegans. Dev Biol 56, 110-156

4. Kimble J and Hirsh D (1979) The postembryonic cell lineages of the hermaphrodite and male gonads in Caenorhabditis elegans. Dev Biol 70, 396-417

5. Kit S, Beck C, Graham OL and Graham O (1958) Effect 
of 5-Bromodeoxyuridine on Deoxyribonucleic Acid-Thymine Synthesis and Cell Metabolism of Lymphatic Tissues and Tumors Effect of 5-Bromodeoxyuridine on Deoxyribonucleic Acid- Thymine Synthesis and Cell Metabolism of Lymphatic Tissues and Tumors. Cancer Res 18, 598-602

6. Gratzner HG (1982) Monoclonal antibody to 5-bromoand 5-iododeoxyuridine: $\mathrm{A}$ new reagent for detection of DNA replication. Science (New York, N.Y.) 218, 474475

7. Trent JM, Gerner E, Broderick R and Crossen PE (1986) Cell cycle analysis using bromodeoxyuridine: Comparison of methods for analysis of total cell transit time. Cancer Genet Cytogenet 19, 43-50

8. Miller MW and Nowakowski RS (1988) Use of bromodeoxyuridine-immunohistochemistry to examine the proliferation, migration and time of origin of cells in the central nervous system. Brain Res 457, 44-52

9. Dolbeare F, Gratzner H, Pallavicini MG and Gray JW (1983) Flow cytometric measurement of total DNA content and incorporated bromodeoxyuridine. Proc Natl Acad Sci U S A 80, 5573-5577

10. Morstyn G, Pyke K, Gardner J, Ashcroft R, de Fazio A and Bhathal P (1986) Immunohistochemical identification of proliferating cells in organ culture using bromodeoxyuridine and a monoclonal antibody. J Histochem Cytochem 34, 697-701

11. Gray JW, Dolbeare F, Pallavicini MG, Beisker W and Waldman F (1986) Cell cycle analysis using flow cytometry. Int J Radiat Biol Relat Stud Phys Chem Med 49, 237-255

12. Kubbies $M$, Schindler $D$, Hoehn $\mathrm{H}$ and Rabinovitch PS (1985) Cell cycle kinetics by BrdU-Hoechst flow cytometry: an alternative to the differential metaphase labelling technique. Cell Tissue Kinet 18, 551-562

13. Schulte DM, Shapiro I, Reincke $M$ and Beuschlein $F$ (2007) Expression and spatio-temporal distribution of differentiation and proliferation markers during mouse adrenal development. Gene Expr Patterns 7, 72-81

14. Tanaka R, Tainaka M, Ota T et al (2011) Accurate determination of S-phase fraction in proliferative cells by dual fluorescence and peroxidase immunohistochemistry with 5-bromo-2'-deoxyuridine (BrdU) and Ki67 antibodies. J Histochem Cytochem 59, 791-798

15. Chwalinski S, Potten CS and Evans G (1988) Double labelling with bromodeoxyuridine and $[3 \mathrm{H}]$-thymidine of proliferative cells in small intestinal epithelium in steady state and after irradiation. Cell Tissue Kinet 21, 317-329

16. Barker N, van Es JH, Jaks V et al (2008) Very long-term self-renewal of small intestine, colon, and hair follicles from cycling Lgr5 + ve stem cells. Cold Spring Harb Symp Quant Biol 73, 351-356

17. Ito M, Liu Y, Yang Z et al (2005) Stem cells in the hair follicle bulge contribute to wound repair but not to homeostasis of the epidermis. Nat Med 11, 1351-1354

18. Abremski K and Hoess R (1984) Bacteriophage P1 Site-specific Recombination. J Biol Chem 259, 1509-1514

19. Feil R, Wagner J, Metzger D, Chambon P (1997) Regulation of Cre recombinase activity by mutated estrogen receptor ligand-binding domains. Biochem Biophys Res
Commun 237, 752-757

20. Tsien JZ, Chen DF, Gerber D et al (1996) Subregion- and cell type-restricted gene knockout in mouse brain. Cell 87, $1317-1326$

21. Akagi K, Sandig V, Vooijs M et al (1997) Cre-mediated somatic site-specific recombination in mice. Nucleic Acids Res 25, 1766-1773

22. Novak A, Guo C, Yang W, Nagy A and Lobe CG (2000) Z/EG, a double reporter mouse line that expresses enhanced green fluorescent protein upon Cre-mediated excision. Genesis 155, 147-155

23. Srinivas S, Watanabe T, Lin CS et al (2001) Cre reporter strains produced by targeted insertion of EYFP and ECFP into the ROSA26 locus. BMC Dev Biol 1, 4

24. Mao $X$, Fujiwara $Y$, Chapdelaine $A$, Yang $\mathrm{H}$ and Orkin $\mathrm{SH}$ (2001) Activation of EGFP expression by Cre-mediated excision in a new ROSA26 reporter mouse strain. Blood 97, 324-326

25. Cai D, Cohen KB, Luo T, Lichtman JW and Sanes JR (2013) Improved tools for the Brainbow toolbox. Nat Methods 10, 540-547

26. Snippert HJ, van der Flier LG, Sato T et al (2010) Intestinal crypt homeostasis results from neutral competition between symmetrically dividing Lgr5 stem cells. Cell $143,134-144$

27. Livet J, Weissman TA, Kang $\mathrm{H}$ et al (2007) Transgenic strategies for combinatorial expression of fluorescent proteins in the nervous system. Nature 450, 56-62

28. Barker N, van Es JH, Kuipers J et al (2007) Identification of stem cells in small intestine and colon by marker gene Lgr5. Nature 449, 1003-1007

29. Van der Flier LG, Sabates-Bellver J, Oving I et al (2007) The Intestinal Wnt/TCF Signature. Gastroenterology 132, 628-632

30. Van de Wetering $M$, Sancho E, Verweij C et al (2002) The $\beta$-Catenin/TCF-4 Complex Imposes a Crypt Progenitor Phenotype on Colorectal Cancer Cells. Cell 111, 241- 250

31. Barker N, Huch M, Kujala P et al (2010) Lgr5(+ve) stem cells drive self-renewal in the stomach and build longlived gastric units in vitro. Cell Stem Cell 6, 25-36

32. Bush PG, Wokosin DL and Hall AC (2008) Europe PMC Funders Group Two-versus one photon excitation laser scanning microscopy: Critical importance of excitation wavelength. 2008

33. Wang E, Babbey CM and Dunn KW (2005) Performance comparison between the high-speed Yokogawa spinning disc confocal system and single-point scanning confocal systems. J Microsc 218, 148-159

34. Denk W, Strickler JH and Webb WW (1990) Two-photon laser scanning fluorescence microscopy. Science (New York, N.Y.) 248, 73-76

35. Kaiser W and Garrett CGB (1961) Two-photon Excitation in CaF2:EU2 +. Phy Rev Lett 7, 229-232

36. Abella ID (1962) Optical Double-Photon Absorption In Caesium Vapor. Phy Rev Lett 9, 453-455

37. Goeppert-Mayer M (1930) Ueber Elementarakte mit zwei Quantenspruengen. 114

38. Chen BC, Legant WR, Wang K et al (2014) Lattice light-sheet microscopy: Imaging molecules to embryos at 
high spatiotemporal resolution. Science 346, 12579981257998

39. Dodt HU, Leischner U, Schierloh A et al (2007) Ultramicroscopy : three-dimensional visualization of neuronal networks in the whole mouse brain. Nat Methods 4, 331-336

40. Huisken J, Swoger J, Del Bene F, Wittbrodt J and Stelzer EH (2004) Optical sectioning deep inside live embryos by selective plane illumination microscopy. Science 305, 13-16

41. Wu Y, Wawrzusin P, Senseney J et al (2013) Spatially isotropic four-dimensional imaging with dual-view plane illumination microscopy. Nat Biotechnol 31, 1032-1038

42. Tomer R, Ye L, Hsueh B and Deisseroth K (2014) Advanced CLARITY for rapid and high-resolution imaging of intact tissues. Nat Protoc 9, 1682-1697

43. Strobl F, Schmitz A and Stelzer EH (2015) Live imaging of Tribolium castaneum embryonic development using light-sheet-based fluorescence microscopy. Nat Protoc $10,1486-1507$

44. Wolf S, Supatto W, Debrégeas G et al (2015) Wholebrain functional imaging with two-photon light-sheet microscopy. Nat Methods 12, 379-380

45. Keller PJ and Ahrens MB (2015) Visualizing Whole-Brain Activity and Development at the Single-Cell Level Using Light-Sheet Microscopy. Neuron 85, 462-483

46. Lemon WC, Pulver SR, Höckendorf B et al (2015) Whole-central nervous system functional imaging in larval Drosophila. Nat Commun 6, 7924

47. Udan RS, Piazza VG, Hsu CW, Hadjantonakis AK and Dickinson ME (2014) Quantitative imaging of cell dynamics in mouse embryos using light-sheet microscopy. Development (Cambridge, England) 141, 4406-4414

48. Keller PJ, Schmidt AD, Wittbrodt J and Stelzer EH (2011) Digital scanned laser light-sheet fluorescence microscopy (DSLM) of zebrafish and Drosophila embryonic development. Cold Spring Harb Protoc 2011, 1235-1243

49. Tomer R, Khairy K, Amat F and Keller PJ (2012) Quantitative high-speed imaging of entire developing embryos with simultaneous multiview light-sheet microscopy. Nat Methods 9, 755-763

50. Soderblom C, Luo X, Blumenthal E et al (2013) Perivascular fibroblasts form the fibrotic scar after contusive spinal cord injury. J Neurosci 33, 13882-13887

51. Spalteholz W (1914) Über das Durchsichtigmachen von menschlichen und tierischen Präparaten und seine theoretischen Bedingungen. Leipzig: S. Hirzel

52. Becker K, Jährling N, Kramer ER, Schnorrer F and Dodt HU (2008) Ultramicroscopy: 3D reconstruction of large microscopical specimens. J Biophotonics 1, 36-42

53. Dent JA, Polson AG and Klymkowsky MW (1989) A whole-mount immunocytochemical analysis of the expression of the intermediate filament protein vimentin in Xenopus. Development 74, 61-74

54. Hama H, Kurokawa H, Kawano H et al (2011) Scale: a chemical approach for fluorescence imaging and reconstruction of transparent mouse brain. Nat Neurosci $14,1481-1488$

55. Ertürk A, Mauch CP, Hellal F et al (2012) Three-dimensional imaging of the unsectioned adult spinal cord to as- sess axon regeneration and glial responses after injury. Nat Med 18, 166-171

56. Ertürk A, Becker K, Jährling N et al (2012) Three-dimensional imaging of solvent-cleared organs using 3DISCO. Nat Protoc 7, 1983-1995

57. Becker K, Jährling N, Saghafi S, Weiler R and Dodt HU (2012) Chemical clearing and dehydration of GFP expressing mouse brains. PLoS One 7, e33916

58. Chung K, Wallace J, Kim SY et al (2013) Structural and molecular interrogation of intact biological systems. Nature 497, 332-337

59. Lee H, Park JH, Seo I, Park SH and Kim S (2014) Improved application of the electrophoretic tissue clearing technology, CLARITY, to intact solid organs including brain, pancreas, liver, kidney, lung, and intestine. BMC Dev Biol 14, 48

60. Yang B, Treweek JB, Kulkarni RP et al (2014) Single-Cell Phenotyping within Transparent Intact Tissue through Whole-Body Clearing. Cell 158, 945-958

61. Blanpain C and Simons BD (2013) Unravelling stem cell dynamics by lineage tracing. Nat Rev Mol Cell Biol 14, 489-502

62. Ritsma L, Ellenbroek SI, Zomer A et al (2014) Intestinal crypt homeostasis revealed at single-stem-cell level by in vivo live imaging. Nature 507, 362-365

63. Clayton E, Doupé DP, Klein AM, Winton DJ, Simons BD and Jones $\mathrm{PH}$ (2007) A single type of progenitor cell maintains normal epidermis. Nature 446, 185-189

64. Alcolea MP, Greulich P, Wabik A, Frede J, Simons BD and Jones PH (2014) Differentiation imbalance in single oesophageal progenitor cells causes clonal immortalization and field change. Nat Cell Biol 16, 615-622

65. Doupé DP, Klein AM, Simons BD and Jones PH (2010) The ordered architecture of murine ear epidermis is maintained by progenitor cells with random fate. Dev Cell 18, 317-323

66. Lopez-Garcia C, Klein AM, Simons BD and Winton DJ (2010) Intestinal stem cell replacement follows a pattern of neutral drift. Science (New York, N.Y.) 330, 822-825

67. Snippert HJ, Schepers AG, van Es JH, Simons BD and Clevers H (2014) Biased competition between Lgr5 intestinal stem cells driven by oncogenic mutation induces clonal expansion. EMBO Rep 15, 62-69

68. Klein AM, Nakagawa $T$, Ichikawa $R$, Yoshida $S$ and Simons BD (2010) Mouse germ line stem cells undergo rapid and stochastic turnover. Cell Stem Cell 7, 214-224

69. Ousset M, Van Keymeulen A, Bouvencourt $G$ et al (2012) Multipotent and unipotent progenitors contribute to prostate postnatal development. Nat Cell Biol 14, 1131-1138

70. Vermeulen L, Morrissey $E$, van der Heijden $M$ et al (2013) Defining stem cell dynamics in models of intestinal tumor initiation. Science (New York, N.Y.) 342, 995-998

71. Kozar S, Morrissey E, Nicholson AM et al (2013) Continuous clonal labeling reveals small numbers of functional stem cells in intestinal crypts and adenomas. Cell Stem Cell 13, 626-633

72. Driessens G, Beck B, Caauwe A, Simons BD and Blanpain C (2012) Defining the mode of tumour growth 
by clonal analysis. Nature 488, 527-530

73. Baker M (2010) Taking a long, hard look. Nature 466, $1137-1140$

74. Qian X, Goderie SK, Shen Q, Stern JH and Temple S (1998) Intrinsic programs of patterned cell lineages in isolated vertebrate CNS ventricular zone cells. Development 3152, 3143-3152

75. Hiraoka Y, Sedat JW and Agard DA (1987) The use of a charge-coupled device for quantitative optical microscopy of biological structures. Science (New York, N.Y.) 238, 36-41

76. Lichtman JW and Conchello JA (2005) Fluorescence microscopy. Nat Methods 2, 910-919

77. Kokkaliaris KD, Loeffler D and Schroeder T (2012) Advances in tracking hematopoiesis at the single-cell level. Curr Opin Hematol 19, 243-249

78. Schroeder T (2008) Imaging stem-cell-driven regeneration in mammals. Nature 453, 345-351

79. Cohen AR, Gomes FL, Roysam B and Cayouette M (2010) Computational prediction of neural progenitor cell fates. Nat Methods 7, 213-218

80. Megason SG and Fraser SE (2003) Digitizing life at the level of the cell: high-performance laser-scanning microscopy and image analysis for in toto imaging of development. Mech Dev 120, 1407-1420

81. Megason SG and Fraser SE (2011) Current challenges in image analysis for in toto imaging of zebrafish. 2011 IEEE International Symposium on Biomedical Imaging: From Nano to Macro, March 2011: 10.1109/ISBI.2011.5872739

82. Krupa M, Mazur E, Szczepańska K, Filimonow K, Maleszewski M and Suwińska A (2014) Allocation of inner cells to epiblast vs primitive endoderm in the mouse embryo is biased but not determined by the round of asymmetric divisions $(8 \rightarrow 16-$ and $16 \rightarrow 32$-cells). Dev Biol 385, 136-148

83. Morris SA, Teo RT, Li H, Robson P, Glover DM and Zernicka-Goetz M (2010) Origin and formation of the first two distinct cell types of the inner cell mass in the mouse embryo. Proc Natl Acad Sci U S A 107, 6364-6369

84. Morris SA, Graham SJ, Jedrusik A and Zernicka-Goetz M (2013) The differential response to Fgf signalling in cells internalized at different times influences lineage segregation in preimplantation mouse embryos. Open Biol 3, 130104

85. Bedzhov I and Zernicka-Goetz M (2014) Self-organizing properties of mouse pluripotent cells initiate morphogenesis upon implantation. Cell 156, 1032-1044

86. Sato T, Vries RG, Snippert HJ et al (2009) Single Lgr5 stem cells build crypt-villus structures in vitro without a mesenchymal niche. Nature 459, 262-265

87. Koo BK, Stange DE, Sato T et al (2012) Controlled gene expression in primary Lgr5 organoid cultures. Nat Methods 9, 81-83

88. Schwank G, Andersson-Rolf A, Koo BK, Sasaki N and Clevers H (2013) Generation of BAC transgenic epithelial organoids. PLoS One 8, e76871

89. Schwank G, Koo BK, Sasselli V et al (2013) Functional repair of CFTR by CRISPR/Cas9 in intestinal stem cell organoids of cystic fibrosis patients. Cell Stem Cell 13, 653-658
90. Sato $T$ and Clevers $H$ (2013) Growing self-organizing mini-guts from a single intestinal stem cell: mechanism and applications. Science (New York, N.Y.) 340, 11901194

91. Greer LF 3rd and Szalay AA (2002) Imaging of light emission from the expression of luciferases in living cells and organisms: a review. Luminescence 17, 43-74

92. Kocher B and Piwnica-Worms D (2013) Illuminating cancer systems with genetically engineered mouse models and coupled luciferase reporters in vivo. Cancer Discov 3, 616-629

93. Woolfenden S, Zhu H and Charest A (2009) A Cre/LoxP conditional luciferase reporter transgenic mouse for bioluminescence monitoring of tumorigenesis. Genesis (New York, N.Y. : 2000) 47, 659-666

94. Sato A, Klaunberg B and Tolwani R (2004) In vivo bioluminescence imaging. Comp Med 54, 631-634

95. Wood S (1958) Pathogenesis of metastasis formation observed in vivo in the rabbit ear chamber. AMA Arch Pathol 66, 550-568

96. Lehr HA, Leunig M, Menger MD, Nolte D and Messmer K (1993) Dorsal skinfold chamber technique for intravital microscopy in nude mice. Am J Pathol 143, 1055-1062

97. Makale $M$ (2007) Intravital imaging and cell invasion. Methods Enzymol 426, 375-401

98. Kedrin D, Gligorijevic B, Wyckoff J et al (2008) Intravital imaging of metastatic behavior through a mammary imaging window. Nat Methods 5, 1019-1021

99. Wyckoff JB, Wang Y, Lin EY et al (2007) Direct visualization of macrophage-assisted tumor cell intravasation in mammary tumors. Cancer Res 67, 2649-2656

100. Zhang L, Lapierre A, Roy B et al (2012) Imaging glioma initiation in vivo through a polished and reinforced thin-skull cranial window. J Vis Exp 69, doi: 10.3791/4201

101. Ritsma L, Steller EJ, Ellenbroek SI, Kranenburg O, Borel Rinkes IH and van Rheenen J (2013) Surgical implantation of an abdominal imaging window for intravital microscopy. Nat Protoc 8, 583-594

102. Weigert R, Sramkova M, Parente L, Amornphimoltham $P$ and Masedunskas A (2010) Intravital microscopy: a novel tool to study cell biology in living animals. Histochem Cell Biol 133, 481-491

103. Pittet MJ and Weissleder R (2011) Intravital imaging. Cell 147, 983-991

104. Ritsma L, Ponsioen B and van Rheenen J (2012) Intravital imaging of cell signaling in mice. IntraVital 1, 1

105. Zhou ZN, Sharma VP, Beaty BT et al (2013) Autocrine HBEGF expression promotes breast cancer intravasation, metastasis and macrophage-independent invasion in vivo. Oncogene 33, 3784-3793

106. Nakasone ES, Askautrud HA, Kees T et al (2012) Imaging tumor-stroma interactions during chemotherapy reveals contributions of the microenvironment to resistance. Cancer Cell 21, 488-503

107. Ritsma L, Ellenbroek SI, Zomer A et al (2014) Intestinal crypt homeostasis revealed at single-stem-cell level by in vivo live imaging. Nature 507, 362-365

108. Sipkins DA, Wei X, Wu JW et al (2005) In vivo imaging of specialized bone marrow endothelial microdomains for tumour engraftment. Nature 435, 969-973 
109. Zomer A, Ellenbroek SI, Ritsma L, Beerling E, Vrisekoop $\mathrm{N}$ and Van Rheenen J (2013) Intravital imaging of cancer stem cell plasticity in mammary tumors. Stem Cells 31, 602-606

110. Yang M, Baranov E, Wang JW et al (2002) Direct external imaging of nascent cancer, tumor progression, angiogenesis, and metastasis on internal organs in the fluorescent orthotopic model. Proc Natl Acad Sci U S A 99, 3824-3829

111. Bins AD, van Rheenen J, Jalink K et al (2007) Intravital imaging of fluorescent markers and FRET probes by DNA tattooing. BMC Biotechnol 7, 2

112. Perentes JY, McKee TD, Ley CD et al (2009) In vivo imaging of extracellular matrix remodeling by tumorassociated fibroblasts. Nat Methods 6, 143-145

113. Chen J, McKay RM and Parada LF (2012) Malignant glioma: lessons from genomics, mouse models, and stem cells. Cell 149, 36-47

114. Schepers AG, Snippert HJ, Stange DE et al (2012) Lineage tracing reveals Lgr5 + stem cell activity in mouse intestinal adenomas. Science (New York, N.Y.) 337, 730-735

115. Jacobs RE, Papan C, Ruffins S, Tyszka JM and Fraser SE (2003) MRI: volumetric imaging for vital imaging and atlas construction. Nat Rev Mol Cell Biol Suppl, SS10SS16

116. Avital I, Summers TA, Steele SR et al (2013) Colorectal cancer stem cells as biomarkers: where it all starts? J Surg Oncol 107, 791-793

117. Shapiro EM, Sharer K, Skrtic S and Koretsky AP (2006) In vivo detection of single cells by MRI. Magnetic resonance in medicine : official journal of the Society of Magnetic Resonance in Medicine / Society of Magnetic Resonance in Medicine 55, 242-249

118. Hao D, Ai T, Goerner F, Hu X, Runge VM and Tweedle M (2012) MRI contrast agents: basic chemistry and safety. J Magn Reson Imaging 36, 1060-1071

119. Tannous BA, Grimm J, Perry KF, Chen JW, Weissleder R and Breakefield XO (2006) Metabolic biotinylation of cell surface receptors for in vivo imaging. Nat Methods 3, 391-396

120. Patrick PS, Hammersley J, Loizou L et al (2014) Dual-modality gene reporter for in vivo imaging. Proc Natl Acad Sci U S A 111, 415-420

121. Cohen B, Ziv K, Plaks V et al (2007) MRI detection of transcriptional regulation of gene expression in transgenic mice. Nat Med 13, 498-503

122. Vande Velde G, Raman Rangarajan J, Vreys R et al
(2012) Quantitative evaluation of MRI-based tracking of ferritin-labeled endogenous neural stem cell progeny in rodent brain. Neurolmage 62, 367-380

123. Vandsburger $M H$, Radoul $M$, Cohen $B$ and Neeman $M$ (2013) MRI reporter genes: applications for imaging of cell survival, proliferation, migration and differentiation. NMR Biomed 26, 872-884

124. Jing XH, Yang L, Duan XJ et al (2008) In vivo MR imaging tracking of magnetic iron oxide nanoparticle labeled, engineered, autologous bone marrow mesenchymal stem cells following intra-articular injection. Joint Bone Spine $75,432-438$

125. Hu SL, Lu PG, Zhang LJ et al (2012) In vivo magnetic resonance imaging tracking of SPIO-labeled human umbilical cord mesenchymal stem cells. J Cell Biochem 113, 1005-1012

126. Jackson J, Chapon C, Jones W, Hirani E, Qassim A and Bhakoo K (2009) In vivo multimodal imaging of stem cell transplantation in a rodent model of Parkinson's disease. J Neurosci Methods 183, 141-148

127. de Vries IJ, Lesterhuis WJ, Barentsz JO et al (2005) Magnetic resonance tracking of dendritic cells in melanoma patients for monitoring of cellular therapy. Nat Biotechnol 23, 1407-1413

128. Mahmoudi $M$, Hosseinkhani $H$, Hosseinkhani $M$ et al (2011) Magnetic resonance imaging tracking of stem cells in vivo using iron oxide nanoparticles as a tool for the advancement of clinical regenerative medicine. Chem Rev 111, 253-280

129. Gurun G, Tekes C, Zahorian J et al (2014) Single-chip CMUT-on-CMOS front-end system for real-time volumetric IVUS and ICE imaging. IEEE Trans Ultrason Ferroelectr Freq Control 61, 239-250

130. Hong G, Diao S, Chang J et al (2014) Through-skull fluorescence imaging of the brain in a new near-infrared window. Nat Photonics 8, 723-730

131. Guayasamin JM, Castroviejo-Fisher S, Ayarzagüena J, Trueb L and Vilà C (2008) Phylogenetic relationships of glassfrogs (Centrolenidae) based on mitochondrial and nuclear genes. Mol Phylogenet Evol 48, 574-595

132. Mali P, Aach J, Stranges PB et al (2013) CAS9 transcriptional activators for target specificity screening and paired nickases for cooperative genome engineering. Nat Biotechnol 31, 833-838

133. Ran FA, Hsu PD, Lin CY et al (2013) Double nicking by RNA-guided CRISPR Cas9 for enhanced genome editing specificity. Cell 154, 1380-1389 